R.C. Petersen, PhD, MD

R.O. Roberts, MB ChB, MS

D.S. Knopman, MD

Y.E. Geda, MD, MSc

R.H. Cha, MS

V.S. Pankratz, PhD

B.F. Boeve, MD

E.G. Tangalos, MD

R.J. Ivnik, PhD

W.A. Rocca, MD, MPH

Address correspondence and reprint requests to Dr. R.C. Petersen, Department of Neurology, Mayo Clinic, 200 First Street SW, Rochester, MN 55905

peter8@mayo.edu

Supplemental data at www.neurology.org

\section{Prevalence of mild cognitive impairment is higher in men}

\author{
The Mayo Clinic Study of Aging
}

and

\section{ABSTRACT}

Objective: We investigated the prevalence of mild cognitive impairment (MCI) in Olmsted County, $M N$, using in-person evaluations and published criteria.

Methods: We evaluated an age- and sex-stratified random sample of Olmsted County residents who were 70-89 years old on October 1, 2004, using the Clinical Dementia Rating Scale, a neurologic evaluation, and neuropsychological testing to assess 4 cognitive domains: memory, executive function, language, and visuospatial skills. Information for each participant was reviewed by an adjudication panel and a diagnosis of normal cognition, $\mathrm{MCl}$, or dementia was made using published criteria.

Results: Among 1,969 subjects without dementia, 329 subjects had $\mathrm{MCl}$, with a prevalence of 16.0\% (95\% confidence interval [Cl] 14.4-17.5) for any $\mathrm{MCl}, 11.1 \%(95 \% \mathrm{Cl} 9.8-12.3)$ for amnestic $\mathrm{MCl}$, and $4.9 \%(95 \% \mathrm{Cl} 4.0-5.8)$ for nonamnestic $\mathrm{MCl}$. The prevalence of $\mathrm{MCl}$ increased with age and was higher in men. The prevalence odds ratio (OR) in men was $1.54(95 \% \mathrm{Cl}$ 1.21-1.96; adjusted for age, education, and nonparticipation). The prevalence was also higher in subjects who never married and in subjects with an APOE $\epsilon 3 \epsilon 4$ or $\epsilon 4 \epsilon 4$ genotype. $\mathrm{MCl}$ prevalence decreased with increasing number of years of education ( $p$ for linear trend $<0.0001$ ).

Conclusions: Our study suggests that approximately $16 \%$ of elderly subjects free of dementia are affected by $\mathrm{MCl}$, and amnestic $\mathrm{MCl}$ is the most common type. The higher prevalence of $\mathrm{MCl}$ in men may suggest that women transition from normal cognition directly to dementia at a later age but more abruptly. Neurology ${ }^{\circledR}$ 2010;75:889-897

\section{GLOSSARY}

$\mathbf{A D}=$ Alzheimer disease; $\mathbf{a}-\mathbf{M C l}=$ amnestic mild cognitive impairment; $\mathbf{C D R}=$ Clinical Dementia Rating scale; $\mathbf{C l}=$ confidence interval; $\mathbf{D S M}$-IV = Diagnostic and Statistical Manual of Mental Disorders, 4th edition; FAQ = Functional Activities Questionnaire; $\mathbf{M C I}$ = mild cognitive impairment; $\mathbf{n a -} \mathbf{M C I}=$ nonamnestic mild cognitive impairment; $\mathbf{O R}$ = odds ratio; $\mathbf{S T M S}=$ Short Test of Mental Status; TICS-m = Telephone Interview for Cognitive Status-modified; WAIS-R = Wechsler Adult Intelligence Scale-Revised.

The field of aging and dementia is moving toward an earlier identification of clinical impairment, and the construct of mild cognitive impairment (MCI) has played a pivotal role. ${ }^{1,2} \mathrm{MCI}$ is considered an intermediate state between the cognitive changes of aging and the earliest clinical features of dementia, particularly Alzheimer disease (AD). ${ }^{3}$ In recent years, the construct has been broadened to include other aspects of cognitive function beyond memory impairment. ${ }^{4,5}$

There have been several recent epidemiologic studies on MCI, but most investigators retrofitted the criteria for MCI to previously collected clinical information, used a variety of detection procedures, and implemented the MCI diagnostic criteria using different algorithms. ${ }^{6,7} \mathrm{By}$ contrast, we evaluated in person a population-based sample specifically to detect MCI and its subtypes using published diagnostic criteria.

From the Department of Neurology (R.C.P., D.S.K., B.F.B., W.A.R.), the Divisions of Epidemiology (R.C.P., R.O.R., Y.E.G., W.A.R.) and Biomedical Statistics and Informatics (R.H.C., V.S.P.), Department of Health Sciences Research, Department of Psychiatry and Psychology (Y.E.G., R.J.I.), and Division of Primary Care Internal Medicine (E.G.T.), Department of Internal Medicine, College of Medicine, Mayo Clinic, Rochester, MN.

Study funding: Supported by the NIH (P50 AG016574, U01 AG006786, K01 MH068351, and K01 AG028573) and the Robert H. and Clarice Smith and Abigail van Buren Alzheimer's Disease Research Program. The study was made possible by the Rochester Epidemiology Project (R01 AR030582).

Disclosure: Author disclosures are provided at the end of the article. 


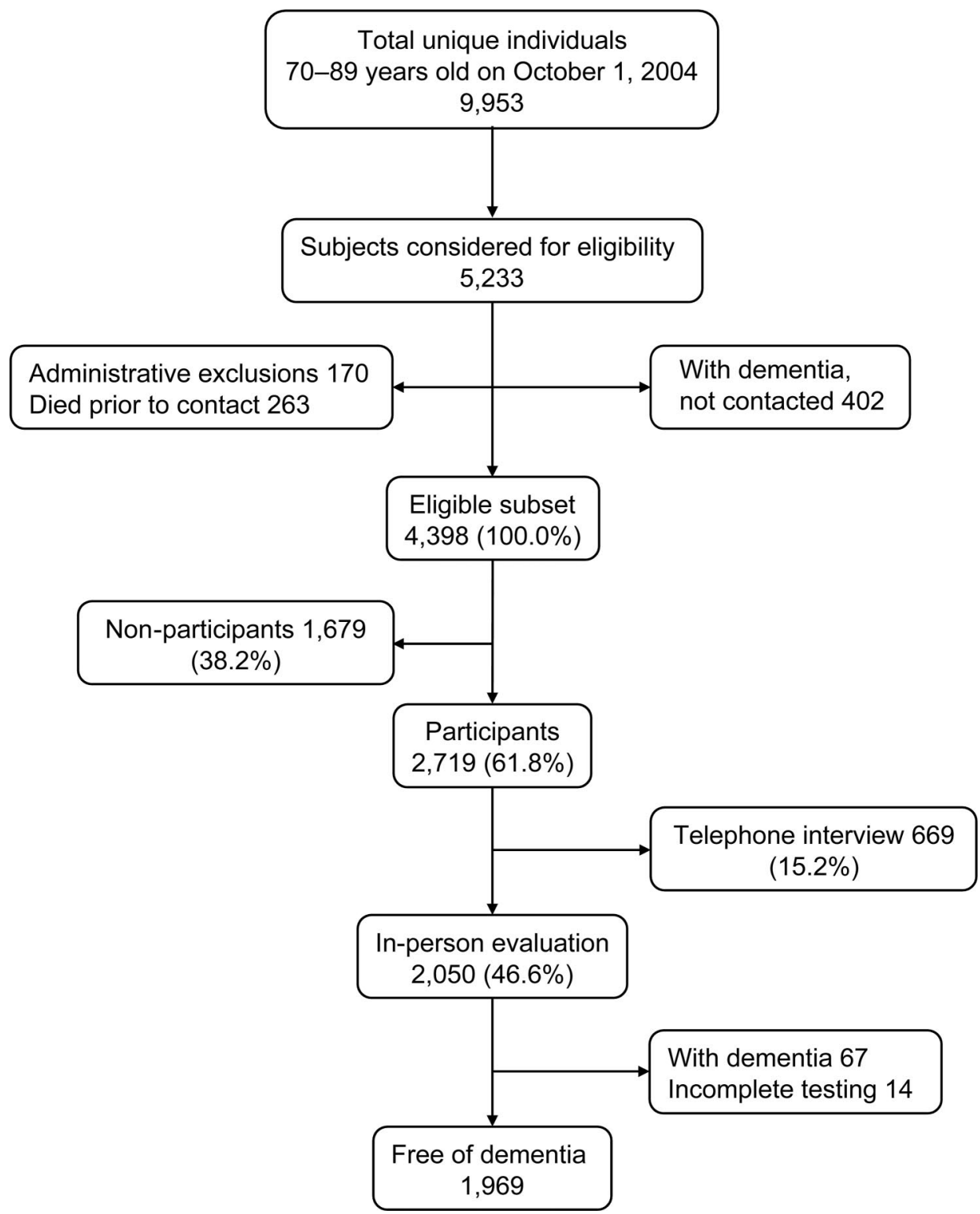

Administrative exclusions involved 56 people who were terminally ill or in hospice and 114 who could not be contacted to confirm eligibility. All percentages refer to the total of 4,398 subjects considered eligible for the study.

METHODS Study sample. This was a prevalence study conducted during the baseline contact to establish a cohort for longitudinal study. The overall study design and methodology have been published in detail elsewhere. ${ }^{8}$ Briefly, all Olmsted County residents who were aged 70-89 years on October 1, 2004, were identified using the medical records-linkage system of the Rochester Epidemiology Project. ${ }^{9}$ We enumerated 9,953 persons aged 70-89 years and randomly selected 5,233 of them for recruitment. We excluded 263 subjects who died before they could be contacted, 56 subjects who were in hospice, and 114 subjects who could not be contacted (figure 1). Subjects with a preexisting diagnosis of dementia were identified by screening their medical record, and the clinical information was reviewed in detail by a neurologist (D.S.K.). Subjects confirmed to have dementia were not invited to participate in the study ( $\mathrm{n}=402)$; however, they were included in the denominator for some of the analyses. A total of 4,398 subjects were considered eligible for participation in the active evaluation (either an in-person evaluation or a telephone interview). The in-person evaluations were conducted from October 1, 2004, through July 31, 2007, and lasted on average approximately 2.5-3.0 hours (approximately 1 hour for cognitive testing).

Measurements of cognitive status. Each participant completed an in-person evaluation including 3 components: 1) interview by a nurse or study coordinator to collect medical and neurologic history, to assess functional abilities, and to document risk factors; 2) a neurologic evaluation; and 3) neuropsychological testing. The interview included a short set of questions about memory administered directly to the participant, and the Clinical Dementia Rating Scale $(\mathrm{CDR})^{10}$ and the Functional Activities Questionnaire (FAQ) ${ }^{11}$ administered to the informant. The neurologic evaluation was performed by a physician and included administration of the Short Test of Mental Status (STMS), ${ }^{12}$ medical history review, and a complete neurologic examination. 
Neuropsychological testing was performed using 9 cognitive tests to assess 4 cognitive domains: memory (Logical Memory-II [delayed percent retention] and Visual Reproduction-II [delayed percent retention] from Wechsler Memory Scale-Revised and delayed percent retention from the Auditory Verbal Learning Test ${ }^{13}$ ); executive function (Trail Making Test B and Digit Symbol Substitution from Wechsler Adult Intelligence ScaleRevised [WAIS-R]); language (Boston Naming Test and category fluency); and visuospatial skills (Picture Completion and Block Design from the WAIS-R). We transformed the raw scores on each test into age-adjusted scores using normative data from the Mayo's Older American Normative Studies. These adjusted scores were scaled to have a mean of 10 and a SD of $3 .^{13}$ We then obtained domain scores by summing the adjusted and scaled scores of the tests included within each domain. The domain scores were also scaled to allow comparisons across domains.

Subjects who refused the in-person evaluation but accepted a telephone interview were administered a structured questionnaire including the Telephone Interview for Cognitive Statusmodified (TICS-m).${ }^{14}$ However, because the TICS-m was found to perform only fairly well in separating MCI from either normal cognition or dementia, we excluded from this study the 669 subjects who only accepted a telephone interview. ${ }^{15}$

Demographic and clinical factors. Date of birth, number of years of education, marital status, prior occupation, and history of diabetes, hypertension, coronary heart disease, and depression were obtained from the nurse interview and risk factors assessment, and a history of stroke and of other conditions possibly related to cognitive performance was obtained by the physician. Whenever possible, these comorbidities were confirmed with information from the medical records-linkage system. ${ }^{8,16}$

Diagnostic categories. The performance of a person in a particular cognitive domain was measured by comparing the person's domain score with the score in normal subjects, available from normative work conducted in this same population. ${ }^{13,17}$ Subjects with scores of $1.0 \mathrm{SD}$ or greater below the age-specific mean in the general population were considered for a possible cognitive impairment. However, the final decision about impairment in any cognitive domain was not based on a simple computer algorithm but rather on a consensus agreement among the examining physician, nurse, and neuropsychologist taking into account education, prior occupation, visual or hearing deficits, and other information. ${ }^{8}$

MCI was defined according to the following published criteria: 1) cognitive concern by subject, informant (from CDR), or nurse or physician; 2) impairment in 1 or more of the 4 cognitive domains (from cognitive battery); 3) essentially normal functional activities (from the CDR and the FAQ); and 4) absence of dementia $(D S M-I V) .{ }^{4,18}$ Subjects with MCI were categorized as having amnestic MCI (a-MCI) if the memory domain was impaired or nonamnestic MCI (na-MCI) if there was no impairment in memory.

A diagnosis of dementia was based on the criteria in the $D S M-I V .{ }^{18}$ Subjects were characterized as cognitively normal according to published normative data developed on this community. ${ }^{13}$ The cognitive status of subjects as measured at the time of the in-person examination was assumed to be the same as on October 1, 2004. This retrodating of cognitive status allowed us to compute point prevalence figures using October 1, 2004, as the prevalence day.
Statistical analyses. For the 4 age and sex strata included in the original sampling scheme, point prevalence was computed directly by dividing the number of prevalent cases of MCI by the population in the corresponding stratum (age- and sex-specific prevalence figures for men aged $70-79$ and $80-89$ years, and women aged $70-79$ and $80-89$ years). Whenever multiple strata were combined, the estimate for each stratum was weighted by its frequency in the total Olmsted County population (direct standardization to the Olmsted County population on October 1, 2004). ${ }^{19}$ Similarly, prevalence figures by education, marital status, and $A P O E$ genotype were standardized by age and sex. In our primary analyses, we estimated the prevalence of MCI considering only the population without dementia in the denominator. However, in secondary analyses, we also included subjects with dementia in the denominator. The denominators including dementia were obtained by incorporating and reproportioning both the subjects with previously diagnosed dementia who were excluded from the study and those found at the in-person evaluation.

To investigate possible biases caused by the subjects who did not participate in the study, we used the propensity score method. ${ }^{3,20}$ Information for nonparticipants was available from the medical records-linkage system for $97 \%$ of all subjects originally sampled. ${ }^{8}$ First, we used logistic regression models to estimate the effect of age, sex, and years of education on participation. ${ }^{20,21}$ Second, we used the reciprocal of the participation probabilities for each subject as weights to estimate $\mathrm{MCI}$ prevalence figures adjusted for nonparticipation. Although estimates adjusted for nonparticipation were similar to the unadjusted estimates, the primary results presented in tables and figures are all adjusted for nonparticipation.

We also conducted a set of case-control analyses comparing the 329 subjects found to have MCI (prevalent MCI) with the 1,640 subjects who were found to be cognitively normal. For several demographic variables, we computed prevalence odds ratios (OR) and 95\% confidence intervals (CI) adjusted for age ( $\geq 80$ vs $<80$ years), sex, years of education ( $\leq 12$ vs $>12$ years), and nonparticipation (reciprocal probability weighting) using logistic regression models.

To explore the higher prevalence of MCI in men, we investigated the possible confounding effect of several clinical comorbidities (diabetes, hypertension, stroke, coronary heart disease, depression), the Charlson index of comorbidity ( $<2 \mathrm{vs} \geq 2$ ), and $A P O E$ genotype (carriers vs noncarriers of $\epsilon 4$ ). We also assessed potential confounding effects of type of informant (spouse or offspring vs other [e.g., more distant relatives, caregivers]) and marital status (currently married vs previously married or never married). All models also included age and years of education. Finally, we assessed potential effect modification by these same variables by including interaction terms with sex in the logistic regression models.

Standard protocol approvals, registrations, and patient consent. The study was approved by the institutional review boards of the Mayo Clinic and of Olmsted Medical Center. Written informed consent was obtained for all participants who were examined as part of the study.

RESULTS Study sample. Of the 4,398 subjects eligible to participate in the active evaluation, 2,719 agreed to participate $(61.8 \%$ response) in an inperson evaluation $(\mathrm{n}=2,050)$ or in a telephone interview ( $\mathrm{n}=669$; figure 1 ). Comparison of 
participants and nonparticipants using information obtained from the medical records-linkage system showed that nonparticipants were older, more often men, less educated, and more likely to have diabetes or greater comorbidities. ${ }^{8}$ Subjects who accepted only the telephone interview were excluded from the analyses presented here.

Overall results. Of the 2,050 subjects who participated in the in-person evaluation, 67 (3.3\%) had a dementia that had not been detected by our review of the medical records, $14(0.7 \%)$ had incomplete cognitive testing, $1,640(80.0 \%)$ were cognitively normal, and 329 (16.0\%) had MCI (figure 1). Among subjects with MCI, 237 (11.6\%) had a-MCI (145 [7.1\%] single domain; 92 [4.5\%] multiple domain)

\begin{tabular}{|c|c|c|c|}
\hline \multirow{2}{*}{$\begin{array}{l}\text { Table } 1 \text { Characterist } \\
\text { and women }\end{array}$} & \multirow[b]{2}{*}{ Men, n (\%) } & \multirow[b]{2}{*}{ Women, $\mathrm{n}(\%)$} & \multirow[b]{2}{*}{ Both sexes, $n(\%)^{a}$} \\
\hline & & & \\
\hline \multicolumn{4}{|l|}{ Age, y } \\
\hline $70-74$ & 316 (31.5) & 269 (27.8) & $585(29.7)$ \\
\hline $75-79$ & 264 (26.3) & $210(21.7)$ & $474(24.1)$ \\
\hline $80-84$ & $307(30.6)$ & 337 (34.9) & $644(32.7)$ \\
\hline $85-89$ & $115(11.5)$ & $151(15.6)$ & 266 (13.5) \\
\hline $70-79$ & $580(57.9)$ & 479 (49.5) & $1,059(53.8)$ \\
\hline $80-89$ & $422(42.1)$ & $488(50.5)$ & 910 (46.2) \\
\hline Total & $1,002(100)$ & 967 (100) & $1,969(100)$ \\
\hline \multicolumn{4}{|l|}{ Education, $y$} \\
\hline$>16$ & $233(23.3)$ & $95(9.8)$ & $328(16.7)$ \\
\hline $13-16$ & 311 (31.0) & $411(42.5)$ & $722(36.7)$ \\
\hline $9-12$ & $365(36.4)$ & $413(42.7)$ & 778 (39.5) \\
\hline$<9$ & $93(9.3)$ & $48(5.0)$ & $141(7.2)$ \\
\hline \multicolumn{4}{|l|}{ Marital status } \\
\hline Married & 821 (81.9) & 389 (40.2) & $1,210(61.5)$ \\
\hline Previously married ${ }^{b}$ & $162(16.2)$ & 505 (52.2) & 667 (33.9) \\
\hline Never married & $19(1.9)$ & $73(7.5)$ & $92(4.7)$ \\
\hline \multicolumn{4}{|l|}{ APOE $\epsilon 4$ allele $^{c}$} \\
\hline$\epsilon 3 \in 4, \epsilon 4 \in 4$ & 212 (22.2) & 211 (22.9) & $423(22.5)$ \\
\hline$\epsilon 2 \epsilon 2, \epsilon 2 \epsilon 3$ & $131(13.7)$ & $128(13.9)$ & 259 (13.8) \\
\hline$\epsilon 3 \epsilon 3$ & $589(61.7)$ & $563(61.0)$ & $1,152(61.4)$ \\
\hline$\epsilon 2 \epsilon 4$ & 22 (2.3) & $20(2.2)$ & $42(2.2)$ \\
\hline \multicolumn{4}{|l|}{ Functional abilities, $\mathrm{FAQ}^{\mathrm{d}}$} \\
\hline Median (interquartile range) & $0.0(0.0-1.0)$ & $0.0(0.0-1.0)$ & $0.0(0.0-1.0)$ \\
\hline Mean (SD) & 1.08 (2.68) & 0.97 (2.33) & 1.03 (2.51) \\
\hline
\end{tabular}

a Sixty-seven subjects diagnosed with dementia and 14 subjects with incomplete cognitive testing were excluded.

${ }^{\mathrm{b}}$ Widowed, divorced, or separated.

${ }^{c}$ APOE genotype was missing for 48 men and 45 women; percents are among subjects with known genotype.

${ }^{d}$ Functional abilities were measured using the Functional Activities Questionnaire (FAQ) (range 0-30). ${ }^{11}$ and 92 (4.5\%) had na-MCI (69 [3.4\%] single domain; 23 [1.1\%] multiple domain).

Table 1 shows the characteristics of the 1,969 subjects who received a cognitive evaluation and were free of dementia. Consistent with the study design, there were about equal proportions of men and women; $53.3 \%$ had $>12$ years of education, and $61.5 \%$ were currently married; a greater proportion of men $(81.9 \%)$ compared with women $(40.2 \%)$ were currently married. Approximately $23 \%$ of subjects had the APOE $\epsilon 3 \epsilon 4$ or $\epsilon 4 \epsilon 4$ genotype.

The prevalence of MCI in the total population (including dementia cases in the denominator) and adjusted for nonparticipation was $14.3 \%$ for any MCI, $9.9 \%$ for a-MCI, and $4.4 \%$ for na-MCI (table 2 , footnotes). The prevalence of dementia was $10.0 \%$ (95\% CI 8.9-11.2), and $75.7 \%$ of subjects (95\% CI 74.1-77.4) were cognitively normal (data not shown). The combined prevalence of either MCI or dementia was 24.3\% (95\% CI 22.6-25.9); data not shown). Table e-1 (on the Neurology ${ }^{\circledR}$ Web site at www.neurology.org) shows the distribution of the subjects with MCI by the type of concern about cognitive performance and by sex.

MCI prevalence in the population without dementia. Table 2 shows the prevalence, adjusted for nonparticipation, of all MCI, a-MCI, and na-MCI by age and sex among subjects without dementia. The overall age- and sex-adjusted prevalence of MCI was $16.0 \%$ for any MCI, $11.1 \%$ for a-MCI, and $4.9 \%$ for na-MCI. The prevalence of MCI increased with increasing age and was consistently higher in men than women across all ages (figure 2A). The age and sex patterns were similar for all MCI, a-MCI, and na-MCI. In addition, the increase with age was similar across subtypes of MCI (figure $2 \mathrm{C}$ and table e-2). The median FAQ score was 0.0 (interquartile range $0.0-1.0$; mean 0.61 ; SD 1.53 ) in cognitively normal subjects and 1.0 (interquartile range 0.0-4.0; mean 3.10; SD 4.55) in subjects with MCI. Prevalence figures adjusted for nonparticipation (primary results in tables and figures) were somewhat higher than those unadjusted (e.g., the unadjusted overall prevalence of MCI was 14.9\%; 95\% CI 13.7-16.0).

Table 2 also shows the prevalence of MCI by years of education, marital status, and $A P O E$ genotype in men and women separately. The prevalence of MCI decreased markedly with increasing number of years of education from $30.2 \%$ in subjects with $<9$ years of education to $11.0 \%$ in subjects with $>16$ years of education. The pattern was similar for men and women (figure 2B) and across subtypes of MCI (figure 2D and table e-2). The prevalence of MCI was higher in never married subjects than in currently married or previously married subjects, and in subjects with the APOE $\epsilon 3 \epsilon 4$ or $\epsilon 4 \epsilon 4$ genotype (table 2). 
Table 2 Prevalence of all $\mathrm{MCl}$, amnestic $\mathrm{MCl}$, and nonamnestic $\mathrm{MCl}$ by age, sex, and other characteristics ${ }^{\mathrm{a}}$

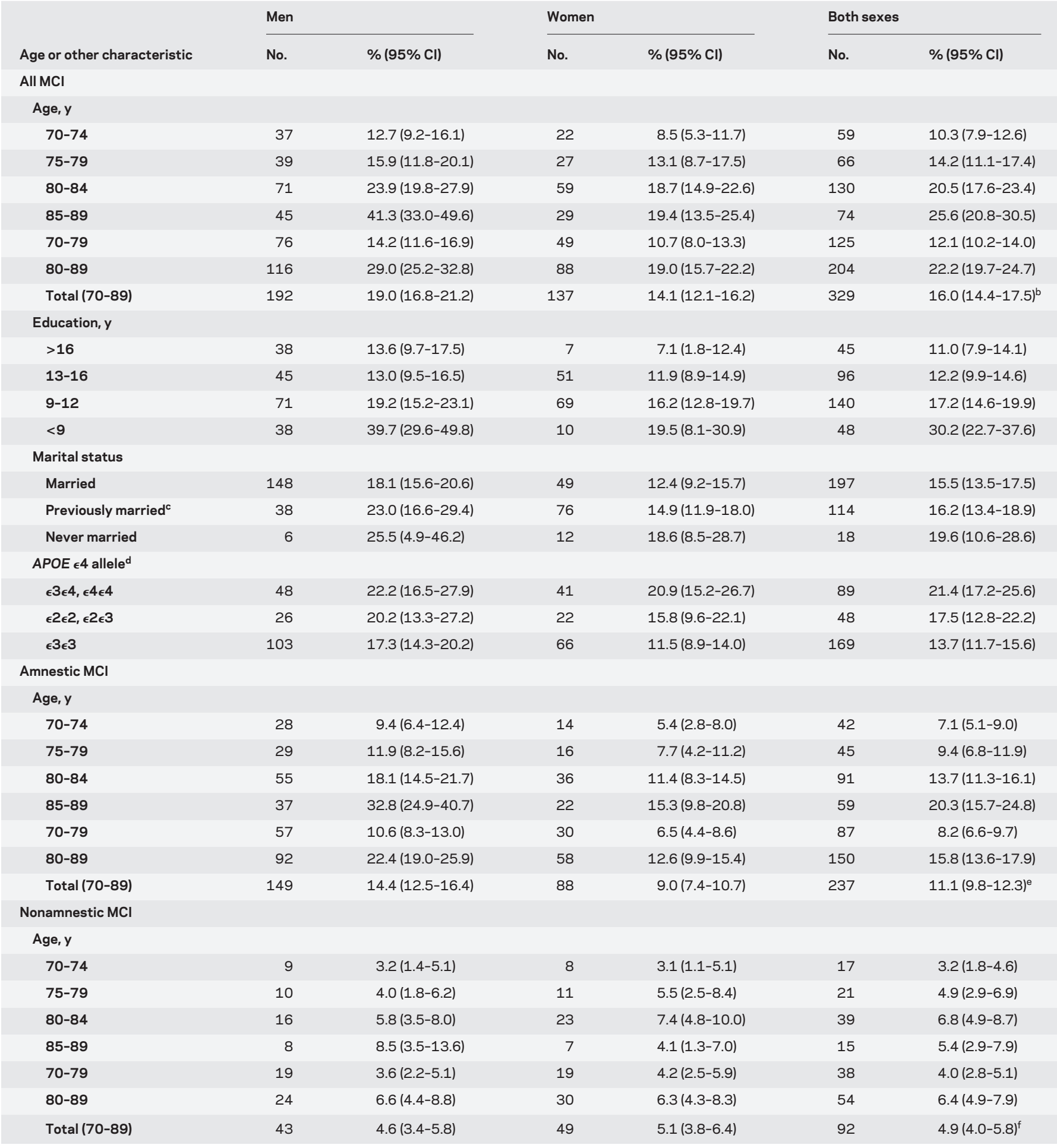

Abbreviations: $\mathrm{Cl}=$ confidence interval; $\mathrm{MCl}=$ mild cognitive impairment.

a Analyses adjusted for nonparticipation using reciprocal probability weighting. Prevalence estimates excluding subjects with dementia from the denominator (the denominators are provided in table 1). Prevalence estimates were directly standardized by age and sex to the Olmsted County population on October 1, 2004, whenever it was applicable.

${ }^{b}$ The prevalence in the total population including dementia cases in the denominator was 14.3 (95\% $\left.\mathrm{Cl} 12.9-15.6\right)$ overall, 17.1 (95\% $\left.\mathrm{Cl} 15.1-19.0\right)$ in men, and 12.6 (95\% Cl 10.8-14.4) in women.

c Widowed, divorced, or separated.

d Subjects with $\epsilon 2 \epsilon 4$ were excluded because of small numbers.

e The prevalence in the total population including dementia cases in the denominator was $9.9(95 \% \mathrm{Cl} 8.8-11.0)$ overall, 13.0 (95\% $\mathrm{Cl} 11.2-14.7)$ in men, and $8.0(95 \% \mathrm{Cl} 6.6-9.5)$ in women.

${ }^{\mathrm{f}}$ The prevalence in the total population including dementia cases in the denominator was $4.4(95 \% \mathrm{Cl} 3.6-5.2)$ overall, 4.1 (95\% $\left.\mathrm{Cl} 3.0-5.1\right)$ in men, and 4.6 $(95 \% \mathrm{Cl} 3.4-5.7)$ in women. 

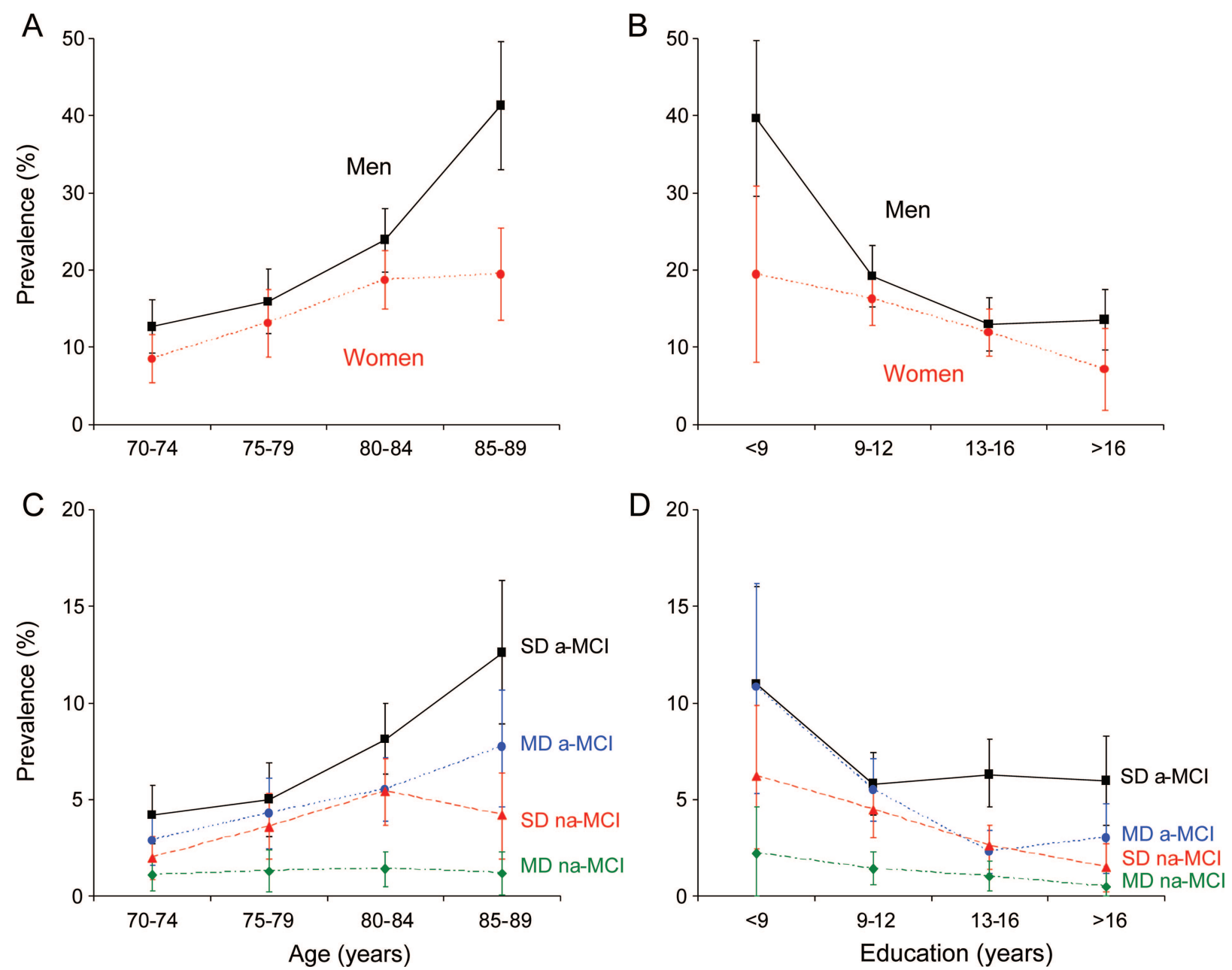

(A) Age- and sex-specific prevalence of $\mathrm{MCl}$ in Olmsted County, MN. Men had consistently higher prevalence than women at all ages. (B) Education- and sex-specific prevalence of $\mathrm{MCl}$. The prevalence decreased with increasing education in both men and women. (C) Age- and type-specific prevalence of $\mathrm{MCl}$. The increase of prevalence with age was consistent for single-domain amnestic $\mathrm{MCl}$ (SD a-MCl), multiple-domain amnestic $\mathrm{MCl}$ (MD a-MCl), single-domain nonamnestic $\mathrm{MCl}$ (SD na-MCl), and multiple-domain nonamnestic $\mathrm{MCl}$ (MD na-MCI). (D) Education- and type-specific prevalence of $\mathrm{MCl}$. The decline in prevalence with increasing education was consistent across the 4 types of $\mathrm{MCl}$.

Case-control analyses. Table 3 shows the results of our case-control analyses with and without adjustment for nonparticipation. The prevalence OR for MCI was increased in older subjects, in men, in subjects who never married, and in subjects with the $A P O E \epsilon 3 \epsilon 4$ or $\epsilon 4 \epsilon 4$ genotype; however, the OR decreased with increasing number of years of education (table 3). The higher prevalence OR of $\mathrm{MCI}$ in men compared with women remained essentially unchanged after adjustment for several demographic variables (age, education, marital status, type of informant), clinical variables (diabetes, hypertension, stroke, coronary artery disease, depression, Charlson index), or $A P O E$ genotype. In addition, there were no significant interactions of sex with age, years of education, or $A P O E$ genotype (data not shown).

DISCUSSION This study provides estimates of the prevalence of $\mathrm{MCI}$, a-MCI, and na-MCI in the com- munity using the diagnostic criteria currently employed by the National Institute on Aging Alzheimer's Disease Center program and the Alzheimer's Disease Neuroimaging Initiative. ${ }^{22}$ This study documented a relatively high prevalence of MCI in the community at $16.0 \%$. The prevalence increased with age, was higher in men, in nevermarried subjects, and in subjects with $A P O E \in 3 \in 4$ or $\epsilon 4 \epsilon 4$ genotype, and decreased with higher levels of education.

We found that a-MCI was 2.3 times more common than na-MCI. Because a-MCI is considered a precursor of $\mathrm{AD}$, this pattern is consistent with the pattern observed in the prevalence of $\mathrm{AD}$ vs other types of dementia. In addition, the combined prevalence of MCI and dementia at $24.3 \%$ highlights the public health impact of these conditions and the urgency for finding therapies. ${ }^{23,24}$ 
Table 3 Case-control analyses comparing 329 subjects with $\mathrm{MCl}$ to 1,640 cognitively normal subjects

\begin{tabular}{|c|c|c|c|c|c|c|}
\hline \multirow{2}{*}{$\begin{array}{l}\text { Demographic } \\
\text { characteristic } \\
\text { or genotype }\end{array}$} & \multicolumn{2}{|c|}{ Exposure frequency } & \multicolumn{2}{|c|}{$\begin{array}{l}\text { Models adjusted for age, sex, } \\
\text { and education }\end{array}$} & \multicolumn{2}{|c|}{$\begin{array}{l}\text { Models further adjusted } \\
\text { for nonparticipation }\end{array}$} \\
\hline & Cases, n (\%) & Controls, $\mathrm{n}(\%)$ & Odds ratio (95\% Cl) & $p$ Value & Odds ratio $(95 \% \mathrm{Cl})$ & $p$ Value \\
\hline \multicolumn{7}{|l|}{ Age at evaluation, y } \\
\hline 70-79 & $103(31.3)$ & $847(51.6)$ & 1.00 (reference) & - & 1.00 (reference) & - \\
\hline $80-89$ & $226(68.7)$ & $793(48.4)$ & $2.31(1.79-2.99)$ & $<0.0001$ & $2.26(1.74-2.92)$ & $<0.0001$ \\
\hline \multicolumn{7}{|l|}{ Sex (male vs female) } \\
\hline Women & $137(41.6)$ & $830(50.6)$ & 1.00 (reference) & - & 1.00 (reference) & - \\
\hline Men & $192(58.4)$ & $810(49.4)$ & $1.52(1.18-1.95)$ & $<0.001$ & $1.54(1.21-1.96)$ & 0.001 \\
\hline \multicolumn{7}{|l|}{ Education, $y$} \\
\hline$>16$ & 45 (13.7) & $283(17.3)$ & 1.00 (reference) & -- & 1.00 (reference) & $-^{c}$ \\
\hline $13-16$ & 96 (29.2) & 626 (38.2) & $1.05(0.71-1.56)$ & 0.79 & $1.07(0.69-1.66)$ & 0.77 \\
\hline $9-12$ & $140(42.6)$ & 638 (38.9) & $1.48(1.02-2.15)$ & 0.04 & $1.50(0.99-2.28)$ & 0.06 \\
\hline$<9$ & $48(14.6)$ & $93(5.7)$ & 2.87 (1.78-4.63) & $<0.0001$ & $2.82(1.76-4.53)$ & $<0.0001$ \\
\hline \multicolumn{7}{|l|}{ Marital status } \\
\hline Married & $197(59.9)$ & $1,013(61.8)$ & 1.00 (reference) & - & 1.00 (reference) & - \\
\hline Previously married ${ }^{d}$ & $114(34.7)$ & 553 (33.7) & $1.03(0.77-1.38)$ & 0.85 & $1.03(0.78-1.36)$ & 0.82 \\
\hline Never married & $18(5.5)$ & $74(4.5)$ & $1.56(0.88-2.77)$ & 0.12 & $1.62(0.91-2.87)$ & 0.10 \\
\hline \multicolumn{7}{|l|}{ APOE $\epsilon 4$ allele $^{e}$} \\
\hline$\epsilon 3 \epsilon 3$ & $169(55.2)$ & $983(64.3)$ & 1.00 (reference) & - & 1.00 (reference) & - \\
\hline$\epsilon 2 \epsilon 2, \epsilon 2 \epsilon 3$ & 48 (15.7) & 211 (13.8) & $1.40(0.97-2.00)$ & 0.07 & $1.47(1.04-2.08)$ & 0.03 \\
\hline$\epsilon 4 \in 4, \epsilon 3 \in 4$ & 89 (29.1) & 334 (21.9) & $1.62(1.21-2.16)$ & 0.001 & $1.68(1.26-2.24)$ & 0.0004 \\
\hline
\end{tabular}

Abbreviations: $\mathrm{Cl}=$ confidence interval; $\mathrm{MCl}=$ mild cognitive impairment.

${ }^{a}$ Models adjusted for age ( $\geq 80$ vs $<80$ years), sex, and years of education ( $>12$ vs $\leq 12$ years) whenever applicable.

${ }^{b}$ Models adjusted for age, sex, education, and nonparticipation using reciprocal probability weighting.

${ }^{c}$ The $p$ value for a linear trend in the log odds ratios was $<0.0001$.

d Widowed, divorced, or separated.

e Genotype was missing for 18 subjects with $\mathrm{MCl}$ and 75 subjects with normal cognition. Subjects with $\epsilon 2 \epsilon 4$ ( $\mathrm{n}=42 ; 2.2 \%)$ were excluded because of small numbers. The unexpected significant association of prevalent $\mathrm{MCl}$ with the $\epsilon 2 \epsilon 2$ or $\epsilon 2 \epsilon 3$ genotypes may reflect a selective survival of subjects with $\mathrm{MCl}$ and with an $\epsilon 2 \epsilon 2$ or $\epsilon 2 \epsilon 3$ genotype.

Prevalence estimates of MCI vary from studies around the world. ${ }^{25-27}$ This variability may be caused by the population studied, the age distribution and size of the sample, and the use of different implementations of the MCI criteria. In particular, studies used prospective vs retrospective fitting of diagnostic criteria, neuropsychological algorithms vs clinical consensus diagnosis, different types of cognitive instruments, different depth and breadth of in-person evaluations, and different normative data. ${ }^{28} \mathrm{~A}$ major limitation with retrofitting diagnostic criteria for MCI to previously collected neuropsychological data is the need to apply a rigid algorithm. By contrast, multiple data sources were used to make the diagnoses in our study.

The Kungsholmen Project in Sweden used global and domain-specific cognitive measures and yielded a prevalence of $11.1 \%$ in a sample of 379 subjects aged 75-95 years and free of dementia. ${ }^{27}$ A study from Leipzig, Germany, used a 55-point composite instrument and yielded an overall prevalence of $19.2 \%$ in subjects 75 years and older. ${ }^{25}$ The Cardio- vascular Health Study yielded an overall prevalence of $19 \%$ in subjects aged 75 years and older. ${ }^{29}$ The North Manhattan Multi-Ethnic and Multicultural Study used retrospectively applied neuropsychological criteria and yielded prevalence estimates between $21.8 \%$ and $26.9 \% .^{6}$ The prevalence of MCI in the present study was also comparable with the prevalence of cognitive impairment no dementia in the Canadian Study of Health and Aging (16.8\%), ${ }^{30}$ and in the Aging, Demographics, and Memory Study in the United States (22.2\%). ${ }^{31}$ Despite some methodologic differences, most of the studies reported prevalence figures for $\mathrm{MCI}$ or for cognitive impairment no dementia in the $11 \%-20 \%$ range.

An interesting observation in this study was the higher prevalence of MCI in men compared with women. Other investigators have reported a similar pattern using different methods of implementation of the diagnostic criteria for MCI.7,32 By contrast, the higher prevalence of $\mathrm{MCI}$ in men was not observed in other studies. ${ }^{33-35}$ In addition, an 
Italian study and a French study yielded a higher prevalence of MCI in women compared with men. ${ }^{36,37}$ However, the diagnostic criteria for MCI relied on a few psychometric tests, in particular on the Mini-Mental State Examination. ${ }^{37}$

The higher OR of MCI in men remained essentially unchanged after adjustment for several demographic and clinical variables, and $A P O E$ genotype, suggesting that the association was not due to comorbid conditions or to a differential assessment of $\mathrm{MCI}$ in men and women. If the higher prevalence in men is confirmed, it may suggest the interplay of sexspecific risk factors, sex-specific disease course, and sex-specific survival. For example, men may experience cognitive decline earlier in life but more gradually, whereas women may transition from normal cognition directly to dementia at a later age but more abruptly. Sex differences in risk factors and outcomes have been reported for stroke and cardiovascular diseases. ${ }^{38-40}$

A strength of this study was the in-person assessment of MCI prevalence in subjects randomly selected from a complete enumeration of a defined population. This is in contrast to several previous clinic-based studies that showed a narrower spectrum of MCI severity. ${ }^{3}$ For example, the patients with MCI recruited into the Alzheimer's Disease Neuroimaging Initiative had more severe functional impairment at baseline (mean 3.9; SD 4.5; a clinical series of volunteers) than patients with $\mathrm{MCI}$ in our study (mean 3.1; SD 4.6; a population-based series of prevalent cases). ${ }^{22}$

Second, by using information from a medical records-linkage system, we were able to adjust our findings for nonparticipation.

Third, all subjects in this study underwent a detailed in-person assessment. Because subjects with MCI have essentially normal activities of daily living, it is difficult to make a clinical diagnosis of MCI without a thorough evaluation of the subject. We used independently developed normative data from the same community to interpret the psychometric tests, and clinical diagnoses were made by consensus after evaluation of all the data for a given person and involved experienced neuropsychologists. In contrast, studies that used a global measure of cognition to select subjects for further evaluation (e.g., a dementia screening test) may have missed subjects with MCI as was demonstrated in The Cardiovascular Health Study. ${ }^{29}$ Screening has been shown to yield lower estimates of MCI prevalence. ${ }^{33}$

An important limitation of the study was the relatively low participation rate. Despite the use of propensity scores to adjust for nonparticipation, we cannot exclude some residual bias. Second, the pop- ulation of Olmsted County is predominantly white of European ancestry, and the finding may not apply to other ethnic groups. Finally, we will need longitudinal data to determine whether the sex differences observed in prevalence are due to differences in risk or in survival.

\section{AUTHOR CONTRIBUTIONS}

Statistical analysis was conducted by R.H. Cha and Dr. V.S. Pankratz.

\section{DISCLOSURE}

Dr. Petersen serves on scientific advisory boards for Elan Corporation, Wyeth, and GE Healthcare; receives royalties from the publication of Mild Cognitive Impairment (Oxford University Press, 2003); and receives research support from the NIH/NIA (U01 AG 06786 [PI], P50 AG 16574 [PI], U01 AG 024904 [coinvestigator], and R01 AG11378 [coinvestigator]). Dr. Roberts receives research support from the NIH (K01 AG028573 [PI] and U01 AG006786 [coinvestigator]). Dr. Knopman serves/has served on Data Safety Monitoring Boards for Sanofi-Aventis and Eli Lilly and Company; receives research support from Baxter Pharmaceuticals, Elan Corporation, and Forest Laboratories, Inc.; has served as a consultant to GlaxoSmithKline; and serves as Deputy Editor of Neurology ${ }^{\circledR}$. Dr. Geda receives research support from the NIH (K01 MH68351 [PI]; AG06786 [coinvestigator]), Mayo CTSA (RR024150 [Career Transition Award]), the RWJ Foundation (Harold Amos Scholar), and the Robert H. and Clarice Smith and Abigail Van Buren Alzheimer's Disease Research Program. R.H. Cha reports no disclosures. Dr. Pankratz receives research support from the NIH (NCI P30 CA 15083 [statistician], NIAID N01 AI 40065 [coinvestigator], NIA P50 AG 16574 [core leader], and NIA U01 AG 06786 [coinvestigator]). Dr. Boeve receives royalties from the publication of Behavioral Neurology of Dementia (Cambridge Medicine, 2009) and receives research support from Cephalon, Inc., the NIH (P50 AG16574 [coinvestigator], UO1 AG06786 [coinvestigator], and RO1 AG15866 [coinvestigator]), the Alzheimer's Association, and the Center for Inherited Disease Research (U24 AG026395 [coinvestigator]). Dr. Tangalos serves on a Data Safety Monitoring Board for Eli Lilly and Company; serves as a consultant for Purdue University and Amgen; serves on the editorial boards of MD Net Guide, Journal of the American Medical Directors Association, and IM News; has received honoraria for slide development form Takeda Pharmaceutical Company Limited, Novartis, and Ortho Biotech Products, L.P.; receives research support from Baxter International Inc. and Elan Corporation; and serves as a consultant to Novartis. Dr. Ivnik serves on the editorial boards of The Clinical Neuropsychologist and Aging, Neuropsychology, and Cognition; receives royalties from the publication of Clinical Interpretation of the WAIS-III and WMS-III (Academic Press, 2003); and receives research support from the NIH (NIA AG 06786 [coinvestigator] and NIA AG 16574 [coinvestigator Core B]). Dr. Rocca receives research support from the NIH (AR030582 [PI], AG006786 [coinvestigator], and ES010751 [coinvestigator]).

Received December 11, 2009. Accepted in final form May 21, 2010.

\section{REFERENCES}

1. Petersen RC, Roberts RO, Knopman DS, et al. Mild cognitive impairment: ten years later. Arch Neurol 2009;66: 1447-1455.

2. Gauthier S, Reisberg B, Zaudig M, et al. Mild cognitive impairment. Lancet 2006;367:1262-1270.

3. Bennett DA, Wilson RS, Schneider JA, et al. Natural history of mild cognitive impairment in older persons. Neurology 2002;59:198-205.

4. Petersen RC. Mild cognitive impairment as a diagnostic entity. J Intern Med 2004;256:183-194.

5. Winblad B, Palmer K, Kivipelto M, et al. Mild cognitive impairment: beyond controversies, towards a consensus: 
report of the International Working Group on Mild Cognitive Impairment. J Intern Med 2004;256:240-246.

6. Manly JJ, Tang MX, Schupf N, Stern Y, Vonsattel JP, Mayeux R. Frequency and course of mild cognitive impairment in a multiethnic community. Ann Neurol 2008;63: 494-506.

7. Ganguli M, Dodge HH, Shen C, DeKosky ST. Mild cognitive impairment, amnestic type: an epidemiologic study. Neurology 2004;63:115-121.

8. Roberts RO, Geda YE, Knopman DS, et al. The Mayo Clinic Study of Aging: design and sampling, participation, baseline measures and sample characteristics. Neuroepidemiology 2008;30:58-69.

9. Melton LJ 3rd. History of the Rochester Epidemiology Project. Mayo Clin Proc 1996;71:266-274.

10. Morris JC. The Clinical Dementia Rating (CDR): current version and scoring rules. Neurology 1993;43:2412-2414.

11. Pfeffer RI, Kurosaki TT, Harrah CH Jr, Chance JM, Filos S. Measurement of functional activities in older adults in the community. J Gerontol 1982;37:323-329.

12. Kokmen E, Smith GE, Petersen RC, Tangalos E, Ivnik RC. The Short Test of Mental Status: correlations with standardized psychometric testing. Arch Neurol 1991;48: 725-728.

13. Ivnik RJ, Malec JF, Smith GE, et al. Mayo's Older Americans Normative Studies: WAIS-R, WMS-R and AVLT norms for ages 56 through 97. Clin Neuropsychol 1992;6: $1-104$.

14. Plassman BL, Newman TT, Welsh KA, Helms M, Breitner JCS. Properties of the telephone interview for cognitive status: application in epidemiological and longitudinal studies. Neuropsychiatry Neuropsychol Behav Neurol 1994;7:235-241.

15. Knopman DS, Roberts RO, Geda YE, et al. Validation of the Telephone Interview for Cognitive Status-modified in subjects with normal cognition, mild cognitive impairment, or dementia. Neuroepidemiology 2010;34:34-42.

16. Roberts RO, Geda YE, Knopman DS, et al. Association of duration and severity of diabetes mellitus with mild cognitive impairment. Arch Neurol 2008;65:1066-1073.

17. Ivnik RJ, Malec JF, Smith GE, Tangalos EG, Petersen RC. Neuropsychological tests' normal above age 55: COWAT, BNT, MAE token, WRAT-R Reading, AMNART, STROOP, MT, and JLO. Clin Neuropsychol 1996;10: 262-278.

18. American Psychiatric Association. Diagnostic and Statistical Manual of Mental Disorders: DSM-IV. Washington, DC: American Psychiatric Association; 1994.

19. Cochran WG. Sampling Techniques, 3rd ed. New York: Wiley; 1977.

20. Kessler RC, Little RJ, Groves RM. Advances in strategies for minimizing and adjusting for survey nonresponse. Epidemiol Rev 1995;17:192-204.

21. D'Agostino RB Jr, Rubin DB. Estimating and using propensity scores with partially missing data. J Am Stat Assoc 2000;95:749-759.

22. Petersen RC, Aisen PS, Beckett LA, et al. Alzheimer's Disease Neuroimaging Initiative (ADNI): clinical characterization. Neurology 2010;74:201-209.
23. Brookmeyer R, Johnson E, Ziegler-Graham K, Arrighi HM. Forecasting the global burden of Alzheimer's disease. Alzheimers Dement 2007;3:186-191.

24. Wimo A, Jonsson L, Winblad B. An estimate of the worldwide prevalence and direct costs of dementia in 2003. Dement Geriatr Cogn Disord 2006;21:175-181.

25. Busse A, Hensel A, Guhne U, Angermeyer MC, RiedelHeller SG. Mild cognitive impairment: long-term course of four clinical subtypes. Neurology 2006;67:2176-2185.

26. Das SK, Bose P, Biswas A, et al. An epidemiologic study of mild cognitive impairment in Kolkata, India. Neurology 2007;68:2019-2026.

27. Palmer K, Backman L, Winblad B, Fratiglioni L. Mild cognitive impairment in the general population: occurrence and progression to Alzheimer disease. Am J Geriatr Psychiatry 2008;16:603-611.

28. Tschanz JT, Welsh-Bohmer KA, Lyketsos CG, et al. Conversion to dementia from mild cognitive disorder: the Cache County Study. Neurology 2006;67:229-234.

29. Lopez OL, Jagust WJ, DeKosky ST, et al. Prevalence and classification of mild cognitive impairment in the Cardiovascular Health Study Cognition Study: part 1. Arch Neurol 2003;60:1385-1389.

30. Graham JE, Rockwood K, Beattie BL, et al. Prevalence and severity of cognitive impairment with and without dementia in an elderly population. Lancet 1997;349:1793-1796.

31. Plassman BL, Langa KM, Fisher GG, et al. Prevalence of cognitive impairment without dementia in the United States. Ann Intern Med 2008;148:427-434.

32. Koivisto K, Reinikainen KJ, Hanninen T, et al. Prevalence of age-associated memory impairment in a randomly selected population from eastern Finland. Neurology 1995; 45:741-747.

33. Kivipelto M, Helkala EL, Hanninen T, et al. Midlife vascular risk factors and late-life mild cognitive impairment: a population-based study. Neurology 2001;56:1683-1689.

34. Hanninen T, Hallikainen M, Tuomainen S, Vanhanen M, Soininen H. Prevalence of mild cognitive impairment: a population-based study in elderly subjects. Acta Neurol Scand 2002;106:148-154.

35. Solfrizzi V, Panza F, Colacicco AM, et al. Vascular risk factors, incidence of MCI, and rates of progression to dementia. Neurology 2004;63:1882-1891.

36. Di Carlo A, Lamassa M, Baldereschi M, et al. CIND and $\mathrm{MCI}$ in the Italian elderly: frequency, vascular risk factors, progression to dementia. Neurology 2007;68: 1909-1916.

37. Larrieu S, Letenneur L, Orgogozo JM, et al. Incidence and outcome of mild cognitive impairment in a population-based prospective cohort. Neurology 2002;59:1594-1599.

38. Gerber Y, Weston SA, Killian JM, Jacobsen SJ, Roger VL. Sex and classic risk factors after myocardial infarction: a community study. Am Heart J 2006;152:461-468.

39. Fukuda M, Kanda T, Kamide N, Akutsu T, Sakai F. Gender differences in long-term functional outcome after firstever ischemic stroke. Intern Med 2009;48:967-973.

40. Petrea RE, Beiser AS, Seshadri S, Kelly-Hayes M, Kase CS, Wolf PA. Gender differences in stroke incidence and poststroke disability in the Framingham Heart Study. Stroke 2009;40:1032-1037. 